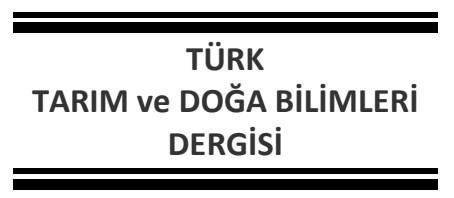

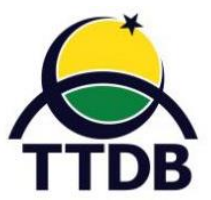

www.dergipark.gov.tr/turkjans

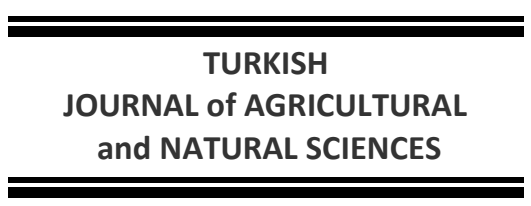

Araştırma Makalesi

\title{
Doğu Anadolu Bölgesindeki Büyükbaş ve Küçükbaş Hayvan Atıklarının Biyogaz Potansiyelinin İncelenmesi
}

\author{
Gizem Hazan ÇAĞLAYAN
}

Muş Alparslan Üniversitesi, Mühendislik-Mimarlık Fakültesi, Çevre Mühendisliği Bölümü, Muş, Türkiye Sorumlu yazar: gh.caglayan@alparslan.edu.tr

Geliş Tarihi: 06.03.2020 Düzeltme Geliş Tarihi: 24.05.2020 Kabul Tarihi: 04.06.2020

Öz

Dünya nüfusunun sürekli artış göstermesi, enerji ihtiyacının karşılanması amacıyla kullanılan fosil kaynakların hızla tükenmesine neden olmaktadır. Ayrıca fosil kaynakların kullanımı ozon tabakasının incelmesi, sera etkisi ve iklim değişikliği gibi çeşitli olumsuz etkilere neden olmaktadır. Bu olumsuz etkileri önlemek amacıyla fosil kaynakların tüketimi sınırlandırılmalı ve çevresel açıdan daha uygun kaynak arayışına gidilmektedir. Yeni kaynak arayışı ile birlikte yenilenebilir enerji kaynakları olarak ifade edilen, kendi kendini yenileyen ve çevre dostu olan enerji türleri ortaya çıkmaktadır. Bu enerji türlerinden biri olan biyogaz enerjisi; organik atıkların belirli işlemlere tabii tutularak elde edilmesi prensibine dayanmaktadır. Bu enerjinin; yakıt, elektrik enerjisi ve ısınma ihtiyacı gibi birçok alanda kullanılabilme özelliği mevcuttur. Biyogaz enerjisinin üretimi ve kullanımı için uygulanabilecek alternatif teknolojiler hızla gelişmektedir. Ülkemizde tarım ve hayvancılık yaygın olduğundan, biyogaz enerjisi için bol miktarda biyokütle kaynağı mevcuttur. Yapılan bu çalışmada; Doğu Anadolu Bölgesi'ne ait 14 ilin büyükbaş ve küçükbaş hayvanlarından oluşacak potansiyel atık miktarı hesaplanmıştır. Bu atıklardan üretilebilecek biyogaz enerjisi ve bu enerjiden faydalanacak kişi sayısı belirlenmiştir. Çalışma sonucunda; Ardahan ili merkez ilçe nüfusunun yaklaşık \%95.4'ünün, gerekli tesis kurulduğu takdirde enerji ihtiyacını biyogaz enerjisinden karşılayabileceği görülmüştür. Ağrı ili merkez ilçesi için bu sayı yaklaşık \%83.6, Tunceli ili merkez ilçesi için ise yaklaşık \%67.6 olarak hesaplanmıştır. Bu veriler göz önünde bulundurularak, bölgeye uygun biyogaz tesislerinin kurulması halinde hem bölgedeki enerji ihtiyacının büyük oranda karşılanacağı hem de çevresel şartların daha kaliteli hale geleceği ifade edilebilir.

Anahtar Kelimeler: Biyogaz, Doğu Anadolu Bölgesi, Hayvansal atık, Yenilenebilir enerji.

\section{Investigation of Biogas Potential of Cattle and Sheep Waste in Eastern Anatolia} Region

\begin{abstract}
The continuous increase in the world population causes the rapid depletion of the existing fossil resources which used for the energy needs. These consumption of sources have many negative effects such as depletion, ozone depletion, greenhouse effect and climate change. In order to prevent these adverse effects, the consumption of fossil resources should be limited and a more environmentally sources should be resaerch. Search for new resources, energy types occur, which are expressed as renewable energy sources and which do not constitute an environmental problem. Biogas energy is one of these energy types; organic wastes are obtained by subjecting to certain processes. This energy; It has property of using in many areas such as fuel, electrical energy and heating need. Nowadays, alternative technologies that can be applied for increasing biogas energy production and use are developing rapidly. Biomass energy is one of the renewable energy sources and it can be said that this type of energy is not at risk of depletion. Since agriculture and animal husbandry are common in our country, there are plenty of biomass resources for biogas production. In this study; the potential
\end{abstract}


amount of waste from bovine and ovine of 14 provinces in the Eastern Anatolia Region was calculated. The biogas potential that can be produced from these wastes and the number of people who will benefit from this potential have been determined. In the results of working; Approximately $95.4 \%$ of the central district population of Ardahan province will be able to meet its energy needs from biogas energy if the required facility is established. This number has been calculated as $83.6 \%$ for the central district of Ağrı and approximately $67.6 \%$ for the central district of Tunceli. Considering these data, it can be stated that if biogas plants suitable for the region are established, both the energy need in the region will be met to a large extent and the environmental conditions will become better.

Keywords: Biogas, East Anatolia Region, Animal waste, Renewable energy.

\section{Giriş}

Insan nüfusunun hızla artması ve sürekli gelişen sanayileşmenin sonucunda, enerji tüketimi de artış göstermektedir. Bu artış sebebiyle en çok tüketilen enerji kaynakları olarak kömür, doğal gaz ve petrol sıralanabilir. Bu kaynaklar fosil kaynak olarak adlandırılır ve mevcut potansiyelleri gün geçtikçe azalmaktadır. Fosil kaynakların enerji hammaddesi olarak kullanılması sonucunda ortaya çıkan çevresel sorunlar, alternatif enerji kaynağı arayışını doğurmaktadır (Hosseini ve Wahid, 2013). Fosil yakıtların yeryüzündeki mevcut rezerv dağılımları petrol eşdeğeri olarak; \%68 kömür, \%18 petrol ve \%14 doğalgaz şeklindedir (Demirtaş ve Gün, 2007). Son yıllarda yapılan çalışmalar; petrolün 2047, doğalgazın 2068, kömürün ise 2140 yılına kadar tükeneceğini göstermektedir. Bu çalışmaların sonuçlarına bakıldığında, yenilenebilir enerji kaynaklarının ne kadar gerekli olduğu açıktır (Baran ve ark., 2017). 2015 yılından itibaren, dünyanın birçok ülkesinde yenilenebilir enerji destek politikaları kabul edilmekte ve Birleşmiş Milletler Sürdürülebilir Kalkınma Hedefleri küresel anlaşmasına bağlı olarak temiz ve yeşil enerjinin kullanımı, birçok hükümetin öncelikli gündemi haline gelmektedir (Sahota ve ark, 2018). Temiz ve yeşil enerji kaynaklarından biri olan biyogaz hem tarımsal hem de çevresel faydalar sağlayan enerji türleri arasındadır. Organik atıkların bertarafı, besin maddelerinin geri dönüşümü ve yeniden kullanımı gibi entegre bir yapıdan oluşan biyogaz tesisleri hem teknoloji hem de uygulama açısından etkili bir yenilenebilir enerji kaynağı olarak ifade edilmektedir (Luo ve ark., 2017).

\section{Biyogaz}

Türkiye; ürettiği enerjinin neredeyse üç katını tüketmektedir ve enerjide dışa bağımlılığı \%70'in üzerindedir. Bunun yanında, özellikle organik atık bakımından yüksek enerji potansiyeline sahip olan ülkemiz, yenilenebilir enerji kaynağı açısından oldukça zengindir (Şenol ve ark., 2017). Ülkemizdeki mevcut organik atıklar genel olarak toplam atıkların \%65'ini oluşturmaktadır. Bu organik atıklar, genellikle kontrolsüz bir şekilde çevreye atılarak çürümeye terk edilmekte ve buna bağlı olarak çevre kirliliği meydana gelmektedir. Organik atıkların değerlendirilmesi ile birlikte çevre kirliliğinin olumsuz etkileri önlenebileceği gibi aynı zamanda enerji ihtiyacının karşılanması açısından büyük fayda sağlanacaktır (Kumbur ve ark., 2015). Gıda atıkları, biyokütle ve hayvansal atıklar vb. organik bileşiklerin oksijensiz ortamda mikroorganizmalar tarafından parçalanması sonucu üretilen biyogaz, insan ve hayvanların biyolojik aktivitesi sonucu oluşan atık ürünlerin fermantasyonu sonucu meydana gelen yanıcı, renksiz ve ISI değeri yüksek bir gaz karışımıdır (Bulut ve Canbaz, 2019). Bu gaz karışımının ana bileşenleri verilen sıcaklıkta su buharı ile doymuş; metan $\left(\mathrm{CH}_{4}\right)(50-65 \%(\mathrm{v} / \mathrm{v}))$ ve karbon dioksit $\left(\mathrm{CO}_{2}\right) \quad(35-50 \% \quad(\mathrm{v} / \mathrm{v}))$ gazlarından oluşmaktadır (Miltner ve ark., 2017). Bu karışıma ek olarak, su buharı $\left(\mathrm{H}_{2} \mathrm{O}\right)$, azot $\left(\mathrm{N}_{2}\right)$, hidrojen $\left(\mathrm{H}_{2}\right)$, oksijen $\left(\mathrm{O}_{2}\right)$, karbon monoksit (CO), hidrojen sülfür $\left(\mathrm{H}_{2} \mathrm{~S}\right)$ ve amonyak $\left(\mathrm{NH}_{3}\right)$ gibi gazlar da bulunabilmektedir (Noyola ve ark., 2006). Biyogazın içerdiği gaz bileşenleri ve $\%$ konsantrasyonları Çizelge 1'de gösterilmektedir.

Çizelge 1. Biyogaz bileşimi (Deviren ve ark., 2017).

\begin{tabular}{cc}
\hline Bileşenler & Hacimsel \% \\
\hline Metan & $50-80$ \\
Karbondioksit & $20-50$ \\
Hidrojen sülfür & $0.0005-0.0002$ \\
Amonyak & $0.0005-0.0001$ \\
Azot & $0-3$ \\
Hidrojen & $0-5$ \\
Su & $0-1$ \\
\hline
\end{tabular}




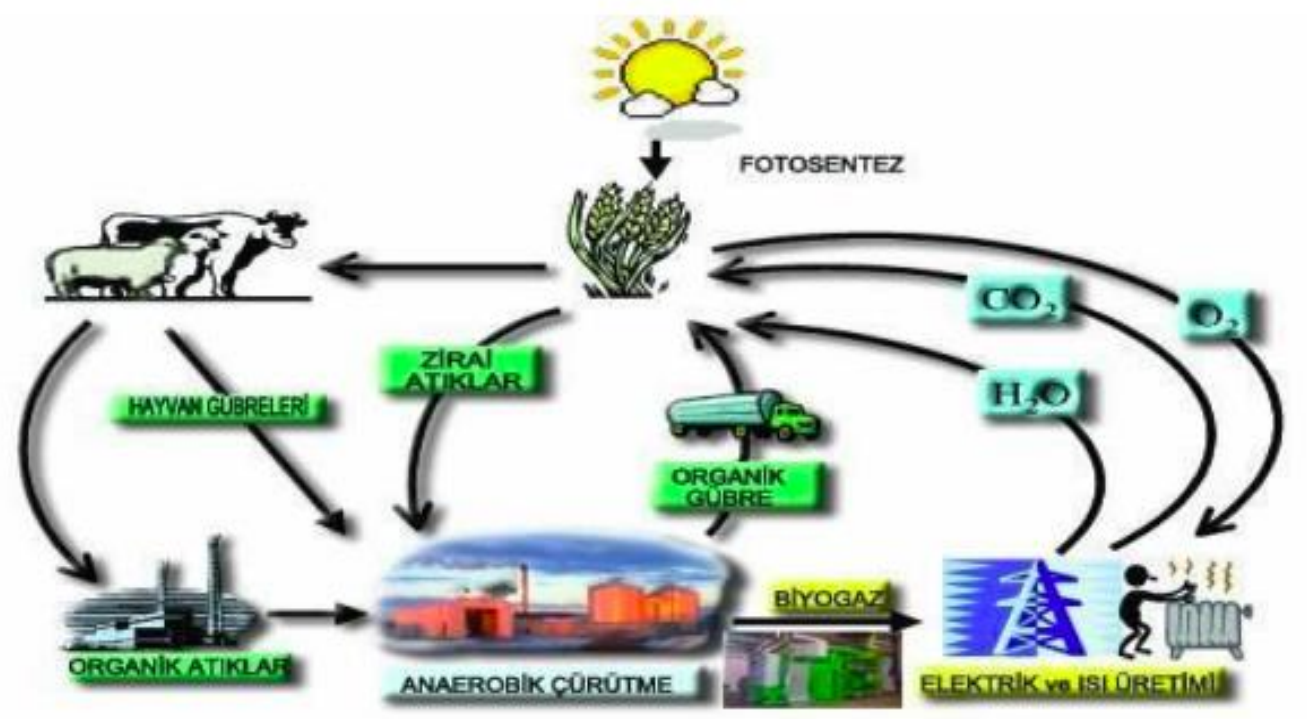

Şekil 1. Biyogaz oluşum çevrimi (Baran ve ark., 2017).

Anaerobik sindirim adı verilen bu proses sayesinde, tarımsal artıklar, atık su arıtma çamuru ve diğer organik atık kaynakları enerji eldesi amacıyla kullanılmaktadır (Aryal ve ark., 2018). Bu proseste organik atıkların kullanılması ile etkili bir atık yönetim sistemi oluşturularak atıklar bertaraf edilir ve bu atıklardan enerji eldesi sağlanır (Köse, 2017). Bu bilgiler ışığında, biyogaz enerjisinin günümüz dünyasında enerji tasarrufu açısından umut verici yenilenebilir enerji kaynaklarından biri olduğu ifade edilebilir (Wang ve ark., 2018). Biyogaz üretiminde kullanılan organik maddeler Çizelge 2'de verilmiştir.

Çizelge 2. Biyogaz üretiminde kullanılan organik atıklar (Deviren ve ark., 2017).

\begin{tabular}{|c|c|}
\hline Organik Maddeler & Atık Türleri \\
\hline $\begin{array}{c}\text { Orman endüstri } \\
\text { atıkları }\end{array}$ & $\begin{array}{l}\text { Sebze, meyve, tahıl ve } \\
\text { yağ endüstri atıkları }\end{array}$ \\
\hline Zirai atıklar & Yemek atıkları \\
\hline Evsel katı atıklar & $\begin{array}{c}\text { Hayvan gübreleri } \\
\text { (büyükbaş, küçükbaş, } \\
\text { tavukçuluk) }\end{array}$ \\
\hline $\begin{array}{l}\text { Kâğıt endüstri } \\
\text { atıkları }\end{array}$ & Şeker endüstri atıkları \\
\hline $\begin{array}{l}\text { Keri ve tekstil } \\
\text { atıkları }\end{array}$ & $\begin{array}{c}\text { Gıda endüstrisi } \\
\text { atıkları }\end{array}$ \\
\hline Bahçe atıkları & $\begin{array}{c}\text { Atık su arıtma tesisi } \\
\text { atıkları }\end{array}$ \\
\hline
\end{tabular}

Her türlü organik maddeden elde edilebilen biyogaz enerjisi için ülkemizde genel olarak hayvan gübreleri esas alınmaktadır (Doruk ve Bozdeveci, 2017). Hayvan gübresi uygun işlemlere tabi tutulmadan çevreye deşarj edildiğinde toprak ve su sistemlerine yönelik ciddi kirliliklere neden olur. (Li ve ark., 2016). Hayvan gübresinden anaerobik sindirim ile elde edilen biyogaz, ortamdaki kokuların ve patojenlerin azalması gibi birçok ekolojik fayda sağlayarak bu kirliliklerin olumsuz etkilerini azaltmaktadır (Khan ve ark., 2017). Ayrıca biyogaz üretiminden elde edilen digestat aynı özelliklere sahip olan bir gübre olarak kullanılabilir. Bu sayede, çiftliklerde kimyasal gübrelerin kullanımı azaltılarak ilave ekonomik faydalar sağlanır ve çevresel açıdan kirletici emisyonlar önlenmiş olur (Dagnall ve ark., 2000).

Biyogaz teknolojisi özellikle gelişmiş ve gelişmekte olan ülkelerde sürekli gündemde kalan ve önemini artıran alternatif enerji kaynağıdır (Koçer ve Kurt, 2013). İklim değişikliği ve fosil yakıtların aşırı kullanımıyla birlikte, biyogaz enerjisinin avantajları giderek daha da belirgin hale gelmektedir (Gao ve ark., 2019). Sera gazı emisyonları ve iklim değişikliği, günümüzde en önemli konular arasında yer almaktadır (Quintino ve ark., 2018). Bütün bu nedenlere dayanarak; son yıllarda hayvansal atıklar, tarımsal atıklar, evsel atıklar ve atık sulardan meydana gelen biyoenerji kaynakları oldukça dikkat çekmekte ve küresel enerji talebinin bir kısmını karşılamak için bu enerji kaynaklarına başvurulmaktadır (Holm-Nielsen 
ve ark., 2009). Yapılan bu çalışmanın amacı; yenilenebilir ve sürdürülebilir bir enerji kaynağı olarak nitelendirilen biyogazın Doğu Anadolu Bölgesi'ndeki mevcut potansiyelini hesaplayarak, bu bölgede kurulacak biyogaz tesislerinin bölgenin enerji talebine sağlayacağı katkıyı incelemektir. Çalışma kapsamında; Doğu Anadolu Bölgesi'nde bulunan 14 ile ait büyükbaş ve küçükbaş hayvan sayıları belirlenmiştir. Bu hayvan sayılarına göre oluşacak atık miktarı, bu atıklardan üretilebilecek biyogaz potansiyeli ve faydalanacak kişi sayısı hesaplanmıştır. Elde edilen bu veriler çizelgeler ve grafikler halinde sunulmuştur.

\section{Materyal ve Yöntem Çalışma Alanı}

Çalışmanın yürütüldüğü Doğu Anadolu Bölgesi Türkiye'nin 7 adet coğrafi bölgesinden biridir. Bölgenin yüz ölçümü 164.000 km²'dir. Ülke topraklarının \%21'ini kaplamaktadır. Bölge 14 ilden oluşmaktadır ve bölgenin başlıca geçim kaynağı tarım ve hayvancılıktır (Wikipedia, 2019).

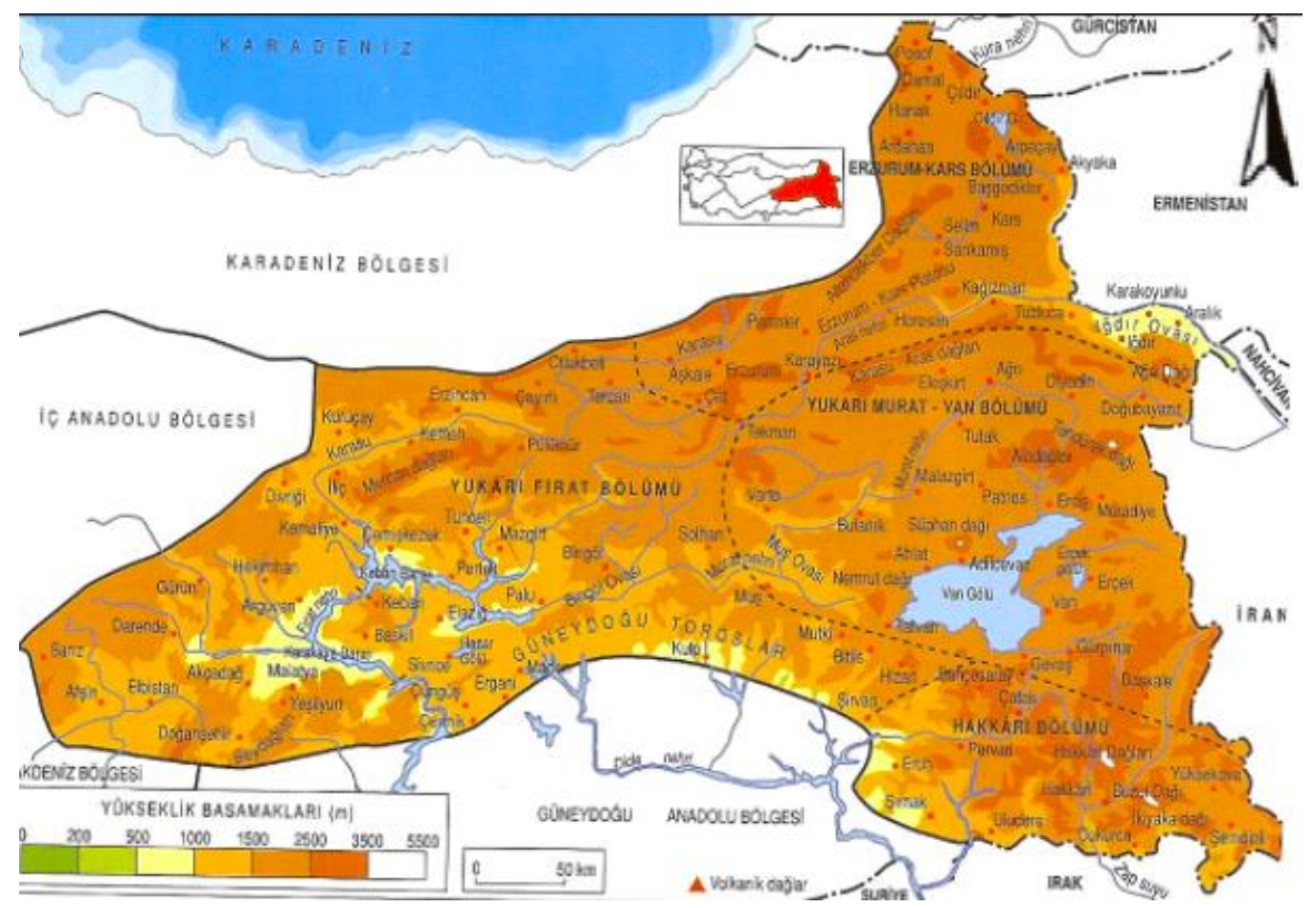

Şekil 2. Doğu Anadolu Bölgesi fiziki haritası (Özgen, 2010).

\section{Çalışma Metodu}

Çalışmada, Doğu Anadolu Bölgesi'ndeki 14 ile ait büyükbaş ve küçükbaş hayvan sayıları 2018 yılına ait Tüik verilerinden elde edilmiştir. Öncelikle günlük atık miktarı belirlenmiş daha sonra bu miktardan üretilebilecek biyogaz potansiyeli hesaplanmıştır. Son olarak ise biyogaz potansiyelinden faydalanacak kişi sayısı tespit edilmiş ve illerin merkez ilçe nüfusları ile faydalanacak kişi sayısı arasında karşılaştırma yapılmıştır. Biyogaz potansiyeli hesaplanırken aşağıda verilen kabuller yapılmıştır;

a) Gübre ile ilgili kabuller:

1 adet büyükbaş hayvandan 3.6 ton yıl $^{-1}$ ve 1 adet küçükbaş hayvandan 0.7 ton $\mathrm{yIl}^{-1}$ yaş gübre eldesi esas alınmıştır. Ayrıca hayvan başına günlük atık miktarı büyükbaş hayvan için $10 \mathrm{~kg}$, küçükbaş hayvan için ise $3 \mathrm{~kg}$ kabul edilmiştir (Yürük ve Erdoğmuş, 2015).

b) Faydalanacak kişi sayısı hesabı ile ilgili kabuller:

Toplam ihtiyaç yaklaşık $3 \mathrm{~m}^{3}$ gün ${ }^{-1}$ olarak alınmıştır. Günlük yemek pişirme ihtiyacı için $0.35 \mathrm{~m}^{3}$ kişi gün ${ }^{-1}$, günlük bir saat aydınlatma kullanımı için $0.15 \mathrm{~m}^{3}$ saat gün ${ }^{-1}$ enerji tüketimi esas alınmış, bir ailenin 5 kişiden oluştuğu ve günlük 8 saat aydınlatma amaçlı enerji ihtiyacı olduğu kabul edilmiştir (Çağlayan ve Koçer, 2014).

c) Biyogaz ile ilgili kabuller:

1 ton sığır gübresinden $33 \mathrm{~m}^{3} \mathrm{yll}^{-1}$ ve bir ton koyun gübresinden ise $58 \mathrm{~m}^{3} \mathrm{yll}^{-1}$ biyogaz 
üretileceği kabul edilmiştir (Yetiş ve ark., 2019). $\mathrm{Bu}$ kabule göre, hesaplama kolaylığı açısından büyükbaş hayvan atığından $\mathrm{kg}$ başına üretilebilecek biyogaz potansiyeli $0.035 \mathrm{~m}^{3}$, küçükbaş hayvan için ise $\mathrm{kg}$ başına üretilebilecek biyogaz potansiyeli $0.060 \mathrm{~m}^{3}$ kabul edilerek her bir il için ayrı ayrı toplam biyogaz potansiyeli hesaplanmıştır.

d) Enerji ile ilgili kabuller:

$1 \mathrm{~m}^{3}$ biyogazın sağladığı ısı miktarı; $3.47 \mathrm{~kg}$ oduna, 0.63 I gaz yağına, $0.43 \mathrm{~kg}$ bütan gazına, 4.7 kWh elektriğe ve 0.8 I benzine eşdeğerdir (Altıkat ve Çelik, 2012).

\section{Araştırma Sonuçları ve Tartışma}

Doğu Anadolu Bölgesinde bulunan büyükbaş ve küçükbaş hayvan sayıları Çizelge 3 'de gösterilmiştir. Çizelge 3 incelendiğinde Doğu Anadolu Bölgesi'ndeki büyükbaş hayvan sayısının \%23.1'inin Erzurum, \%13.5'inin Kars, \%11.66'sinin Ağrı ilinde olduğu görülmektedir. En az sayıdaki büyükbaş hayvan \%1.01 ile Tunceli ilinde bulunmaktadır. Küçükbaş hayvan sayısının ise; \%24.13'ü Van, \%12.04'ü Ağrı, \%9.48'i Muş ilindedir. En az küçükbaş hayvan \%0.67 ile Ardahan ilindedir. Yukarıda verilen kabuller ile 14 ilin büyükbaş ve küçükbaş hayvan sayıları dikkate alınarak her bir ilin toplam biyogaz potansiyeli hesaplanmış ve Çizelge 4'de verilmiştir. Çizelge 4 incelendiğinde, Doğu Anadolu Bölgesine ait toplam biyogaz potansiyelinin en fazla olduğu ilin $539.167 \mathrm{~kg} \cdot \mathrm{m}^{3}$ gün-1 ile Van ili olduğu görülmektedir. Van ilini $403.561 \mathrm{~kg} \cdot \mathrm{m}^{3}$ gün $^{-1}$ toplam biyogaz potansiyeli ile Erzurum ili takip etmektedir. En düşük toplam biyogaz potansiyeline sahip ilin ise $78.135 \mathrm{~kg} \cdot \mathrm{m}^{3}$ gün$^{-1}$ ile Tunceli ili olduğu görülmektedir.

Doğu Anadolu Bölgesi'nde üretilebilecek biyogaz enerjisinden faydalanacak kişi sayısı ve bu sayıların her bir ilin ilçe merkez nüfuslarıyla kıyaslanması amacıyla, bölgedeki 14 ilin merkez ilçelerine ait 2018 yılı nüfus sayıları Tüik verilerinden elde edilmiştir. Tüik verilerine göre Doğu Anadolu Bölgesi 2018 yılı nüfus sayısı Şekil 3'de verilmiştir.

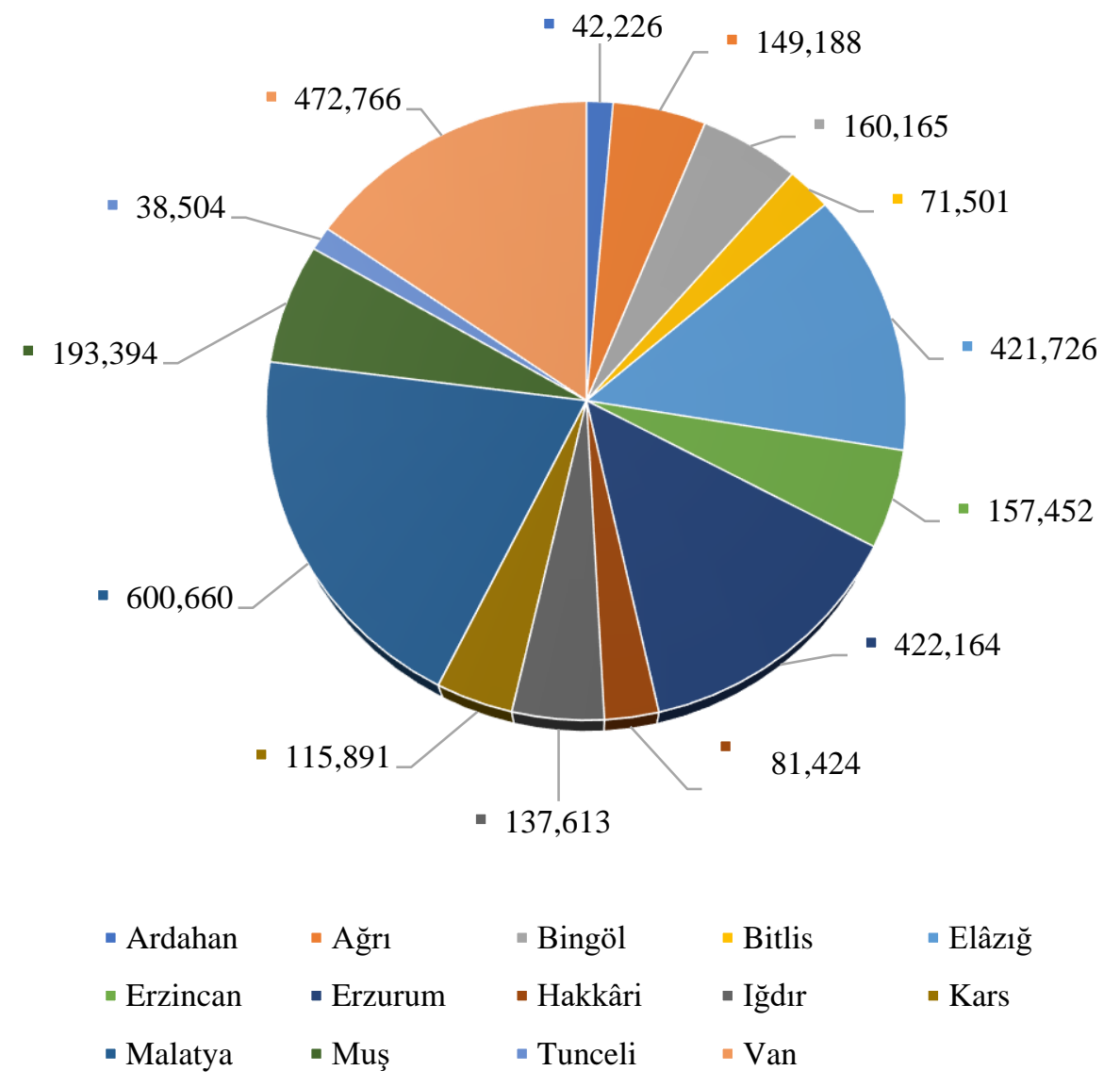

Şekil 3. Doğu Anadolu Bölgesi 2018 yılı nüfusu (TÜiK, 2018). 
Çizelge 3. Doğu Anadolu Bölgesi 2018 yılı büyükbaş ve küçükbaş hayvan sayıları (TÜiK, 2018).

\begin{tabular}{|c|c|c|c|c|}
\hline \multirow{2}{*}{ iller } & \multicolumn{2}{|c|}{ Büyükbaş (Adet) } & \multicolumn{2}{|c|}{ Küçükbaş (Adet) } \\
\hline & Adet & Oran (\%) & Adet & Oran (\%) \\
\hline Ardahan & 306.925 & 9.21 & 74.238 & 0.67 \\
\hline Ağrı & 388.452 & 11.66 & 1.322 .805 & 12.04 \\
\hline Bingöl & 132.772 & 3.99 & 510.781 & 4.65 \\
\hline Bitlis & 94.880 & 2.85 & 645.291 & 5.88 \\
\hline Elâzı̆̆ & 187.418 & 5.63 & 698.745 & 6.36 \\
\hline Erzincan & 114.915 & 3.45 & 434.457 & 3.95 \\
\hline Erzurum & 768.997 & 23.1 & 746.733 & 6.80 \\
\hline Hakkâri & 44.443 & 1.33 & 668.041 & 6.08 \\
\hline Iğdır & 150.633 & 4.52 & 1.028 .322 & 9.36 \\
\hline Kars & 450.101 & 13.5 & 456.500 & 4.16 \\
\hline Malatya & 174.321 & 5.23 & 338.433 & 3.08 \\
\hline Muş & 306.542 & 9.2 & 1.041 .102 & 9.48 \\
\hline Tunceli & 33.939 & 1.01 & 368.089 & 3.36 \\
\hline Van & 177.346 & 5.32 & 2.650 .531 & 24.13 \\
\hline Toplam & 3.331 .684 & 100 & 10.984 .068 & 100 \\
\hline
\end{tabular}

Biyogaz enerjisinden faydalanacak kişi sayısı hesabı yapılırken yukarıda verilen kabuller dikkate alınmıştır. Ayrıca enerji ihtiyacı ve enerji tüketim potansiyelinin merkez ilçelerde daha fazla olduğu düşünülerek her ilin sadece merkez ilçelerinin nüfusu baz alınmıştır. Elde edilen bulgular doğrultusunda bölgenin biyogaz enerjisinden faydalanabilecek kişi sayısı hesaplanmış ve Çizelge 5'de sunulmuştur.

Çizelge 5 incelendiğinde, faydalanacak kişi sayısının illere göre dağılımının toplam biyogaz potansiyeli ile doğru orantılı olduğu açıktır. Toplam biyogaz potansiyelinin en yüksek olduğu Van ve Erzurum illerinde faydalanacak kişi sayısı sırasıyla 179.722 kişi ve 134.520 kişi olarak hesaplanmıştır. Toplam biyogaz potansiyelinin en düşük olduğu Tunceli ilinde ise faydalanacak kişi sayısı 26.045 kişi olarak hesaplanmıştır.

14 ile ait 2018 yılı merkez ilçe nüfusu ile yukarıda hesaplanan biyogaz enerjisinden faydalanacak kişi sayısı arasında karşılaştırma yapılmış ve Şekil 4'te verilmiştir. Bu karşılaştırma sonucunda her bir ile ait büyükbaş ve küçükbaş hayvan atığının, o ilin merkez ilçe nüfusunun enerji ihtiyacının büyük bir kısmını karşılayacak potansiyelde olduğu görülmektedir.

Şekil 4 incelendiğinde, nüfus sayısı ile faydalanacak kişi sayısının birbirine en yakın olduğu ilin Ardahan ili olduğu görülmektedir. 42.226 kişinin yaşadığı merkez ilçede kurulacak bir biyogaz tesisi ile 40.262 kişinin enerji ihtiyacı bu tesisten karşılanabilecektir. Bu sayı merkez ilçe nüfusunun yaklaşık \%95.4'üne tekabül etmektedir. Yine Ağrı ili merkez ilçesinde kurulacak bir biyogaz tesisi ile merkez ilçe nüfusunun yaklaşık \%83.6'sı enerji ihtiyacını biyogaz enerjisinden karşılayacaktır. Toplam biyogaz potansiyelinin en düşük olduğu Tunceli ilinde ise, merkez ilçe nüfusunun faydalanacak kişi sayısına yakın olmasından dolayı il merkezinin \%67.6'sının biyogaz potansiyelinden faydalanabileceği görülmektedir. 
Çizelge 4. Doğu Anadolu Bölgesi'ndeki büyükbaş ve küçükbaş hayvan atıklarından üretilebilecek toplam biyogaz potansiyeli.

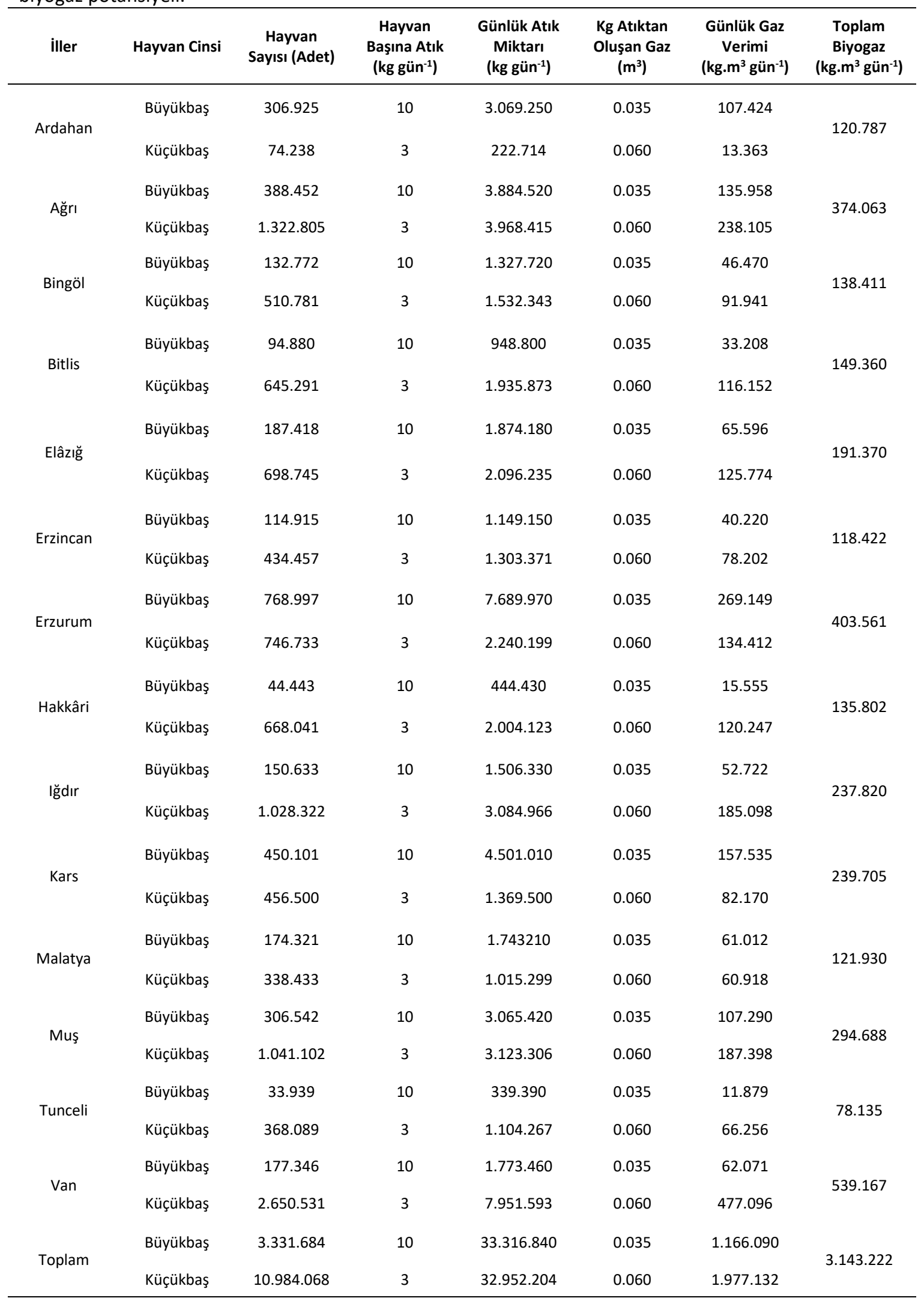


Çizelge 5. Doğu Anadolu Bölgesi 2018 yılı hayvan sayılarından hesaplanan biyogaz miktarından faydalanacak kişi sayısı hesabı.

\begin{tabular}{cccc}
\hline iller & $\begin{array}{c}\text { Toplam Biyogaz } \\
\left(\mathbf{k g}^{\mathbf{3}} \mathbf{m}^{\mathbf{g u ̈ n}} \mathbf{- 1}\right)\end{array}$ & $\begin{array}{c}\text { Toplam Gaz intiyacı } \\
\left(\mathbf{m}^{\mathbf{3}} \mathbf{~ g u ̈ n}^{-1}\right)\end{array}$ & Faydalanacak Kişi Sayısı \\
\hline Ardahan & 120.787 & 3 & 40.262 \\
Ağrı & 374.063 & 3 & 124.688 \\
Bingöl & 138.411 & 3 & 46.137 \\
Bitlis & 149.360 & 3 & 49.787 \\
Elâzı̆̆ & 191.370 & 3 & 63.790 \\
Erzincan & 118.422 & 3 & 39.474 \\
Erzurum & 403.561 & 3 & 134.520 \\
Hakkâri & 135.802 & 3 & 45.268 \\
Iğdır & 237.820 & 3 & 79.273 \\
Kars & 239.705 & 3 & 79.902 \\
Malatya & 121.930 & 3 & 40.643 \\
Muş & 294.688 & 3 & 98.229 \\
Tunceli & 78.135 & 3 & 26.045 \\
Van & 539.167 & 3 & 179.722 \\
Toplam & 3.143 .222 & 3 & 1.047 .740 \\
\hline
\end{tabular}

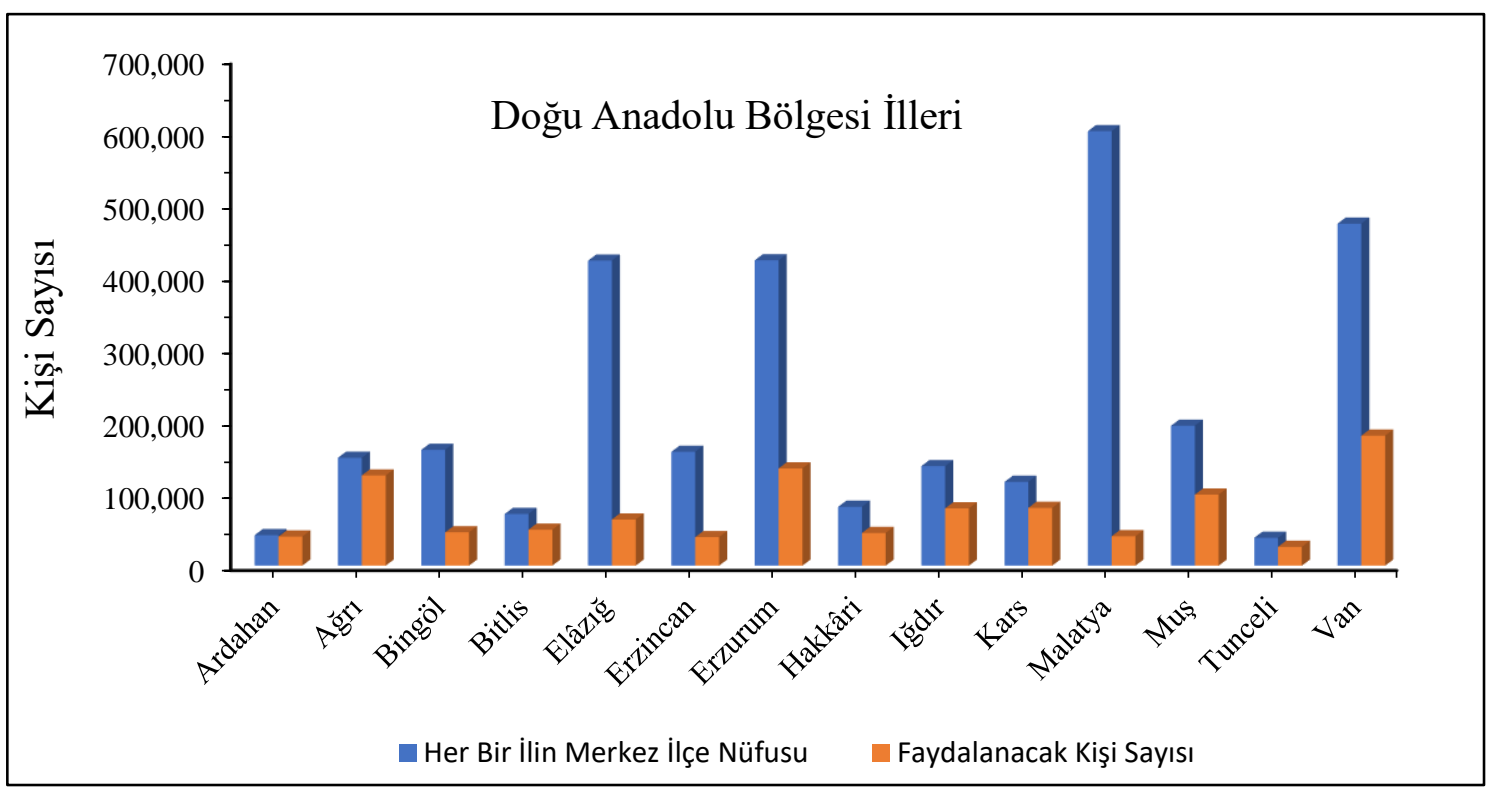

Şekil 4. Merkez ilçe nüfusu ve faydalanacak kişi sayısı kıyası.

\section{Sonuç ve Öneriler}

Mevcut çalışma uygulandığı takdirde, bölge nüfusunun enerji ihtiyacının büyük bir bölümünün biyogaz enerjisinden karşılanabileceği görülmektedir. Bir kişinin günlük ortalama $3 \mathrm{~m}^{3}$ gün-1 enerjiye ihtiyacı olduğu dikkate alınarak, Doğu Anadolu Bölgesi'nde üretilecek biyogaz enerjisinden faydalanacak kişi sayısı toplam 1.047 .740 kişi olarak hesaplanmıştır. Doğu Anadolu Bölgesi 2018 yılı nüfus sayımına göre 14 ilin merkez ilçelerinde toplam 3.064.674 kişi yaşamaktadır. Bu veriler göz önüne alındığında, bölge halkının \%34'ünün enerji ihtiyacını biyogaz enerjisinden karşılayabileceği söylenebilir. 
Yapılan çalışma sonucunda, mevcut bölge için biyogaz enerjisinin etkili bir enerji kaynağı olacağı öngörülmektedir. Bölgedeki ekonomik kalkınma açısından her bir il merkezine kurulacak biyogaz tesislerinin etkin bir rol oynayacağı söylenebilir. Bunun yanı sıra çevresel faktörlerin iyileşmesi ve yaşam kalitesinin yükselmesi açısından biyogaz tesislerinin bölgeye önemli derecede katkı sağlayacağı düşünülmektedir. Tarım potansiyeli yüksek olan bölgede biyokütleden enerji üretimine önem verilmesi ve desteklenmesi ile birlikte enerji ihtiyacında dışa bağımlılığımızın belirli oranda azaltılabileceği düşünülmektedir.

\section{Kaynaklar}

Altıkat, S. ve Çelik, A. 2012. Iğdır ilinin hayvansal atık kaynaklı biyogaz potansiyeli. Iğdır Üniversitesi Fen Bilimleri Enstitüsü Dergisi, 2 (1): 61-66.

Aryal, N., Kvist, T., Ammam, F., Pant, D. ve Ottosen, L. D. 2018. An overview of microbial biogas enrichment. Bioresource technology. 264: 359-369.

Baran, M. F., Lüle, F. ve Gökdoğan, O. 2017. Adıyaman ilinin hayvansal atıklardan elde edilebilecek enerji potansiyeli. Türk Tarım ve Doğa Bilimleri Dergisi. 4 (3): 245-249.

Bulut, A. P. ve Canbaz, G. T. 2019. Hayvan atıklarından Sivas ili biyogaz potansiyelinin araştırılması. Karaelmas Science and Engineering Journal. 9 (1): 110.

Çağlayan, G. H. ve Koçer, N. N. 2014. Muş ilinde hayvan potansiyelinin değerlendirilerek biyogaz üretiminin araştırılması. Muş Alparslan Üniversitesi Fen Bilimleri Dergisi. 2 (1): 215-220.

Dagnall, S., Hill, J. ve Pegg, D. 2000. Resource mapping and analysis of farm livestock manures-assessing the opportunities for biomass-to-energy schemes. Bioresource Technology. 71 (3): 225-234.

Demirtaş, M. ve Gün, V. 2007. Avrupa ve Türkiye'deki biyokütle enerjisi. Celal Bayar Üniversitesi Fen Bilimleri Dergisi, 3 (1): 49-56.

Deviren. H., İlkılıc, C. ve Aydın, S. 2017. Biyogaz üretiminde kullanılabilen materyaller ve biyogazın kullanım alanları. Batman Üniversitesi Yaşam Bilimleri Dergisi. 7 (2/2): 79-89.

Doruk, İ. ve Bozdeveci, A. 2017. Denizli ilinin kırsal kesimlerinde hayvansal kaynaklı atıklardan biyogaz potansiyelinin belirlenmesi. Iğdır Üniversitesi Fen Bilimleri Enstitüsü Dergisi. 7 (3): 181186.

Gao, M., Wang, D., Wang, H., Wang, X. ve Feng, Y. 2019. Biogas potential, utilization and countermeasures in agricultural provinces: a case study of biogas development in henan province, China. Renewable and Sustainable Energy Reviews. 99: 191-200.

Holm-Nielsen, J. B., Al Seadi, T. ve OleskowiczPopiel, P. 2009. The future of anaerobic digestion and biogas utilization. Bioresource Technology. 100 (22): 54785484.

Hosseini, S. E. ve Wahid, M. A. 2013. Feasibility study of biogas production and utilization as a source of renewable energy in Malaysia. Renewable and Sustainable Energy Reviews. 19: 454462.

Khan, I. U., Othman, M. H. D., Hashim, H., Matsuura, T., Ismail, A. F., Rezaei-Dasht Arzhandi M. ve Azelee, I. W. 2017. Biogas as a renewable energy fuel - a review of biogas upgrading, utilisation and storage. Energy Conversion and Management. 150: 277-294.

Koçer, N. N. ve Kurt, G. 2013. Malatya'da hayvancılık potansiyeli ve biyogaz üretimi. SAÜ. Fen Bilimleri Dergisi, 17: 18.

Köse E. T. 2017. Trakya Bölgesi'nde hayvan gübrelerinin biyogaz enerji potansiyelinin belirlenmesi ve sayısal haritaların oluşturulması. Pamukkale Üniversitesi Mühendislik Bilimleri Dergisi. 23 (6): 762-772.

Kumbur, H., Özer, Z., Özsoy, H. D. ve Avcl, E. D. 2015. Türkiye'de geleneksel ve yenilenebilir enerji kaynaklarının potansiyeli ve çevresel etkilerinin karşılaştırılması. III. Yenilenebilir Enerji Sempozyumu. 19-21 Ekim. Mersin.

Li, F., Cheng, S., Yu, H. ve Yang, D. 2016. Waste from livestock and poultry breeding and its potential assessment of biogas energy in rural China. Journal of Cleaner Production. 126: 451-460.

Luo, T., Pan, J., Fu, L., Mei, Z. ve Kong, C. Huang H. 2017. Reducing biogas emissions from village-scale plant with optimal floatingdrum biogas storage tank and operation 
parameters. Applied Energy. 208: 312318.

Miltner, M., Makaruk, A. ve Harasek, M. 2017. Review on available biogas upgrading technologies and innovations towards advanced solutions. Journal of Cleaner Production. 161: 1329-1337.

Noyola, A., Morgan-Sagastume, J. M. ve LopezHernandez, J. E. 2006. Treatment of biogas produced in anaerobic reactors for domestic wastewater: odor control and energy/resource recovery. Reviews in Environmental Science and Biotechnology. 5 (1): 93-114.

Özgen, N. 2010. Doğu Anadolu Bölgesi'nin doğal turizm potansiyelinin belirlenmesi ve planlamaya yönelik öneriler. Uluslararası insan Bilimleri Dergisi. 7 (2): 1407-1438.

Quintino, F. M., Trindade, T. P. ve Fernandes, E. C. 2018. Biogas combustion: chemiluminescence fingerprint. Fuel. 231 (1): 328-340.

Sahota, S., Şah, G., Ghosh, P., Kapoor, R., Sengupta, S., Singh, P., Vijay, V., Sahay, A., Vijay, V. K. ve Thakur, I. S. 2018. Review of trends in biogas upgradation technologies and future perspectives. Bioresource Technology Reports. 1: 7988.

Şenol, H., Elibol, E. A., Açıkel, Ü. ve Şenol, M. 2017. Türkiye'de biyogaz üretimi için başlıca biyokütle kaynakları. BEÜ Fen Bilimleri Dergisi. 6 (2): 81-92.

TÜiK, 2018. Hayvancılık İstatistikleri. (https://biruni.tuik.gov.tr)(03.01.2020)

TÜiK, 2018. Adrese Dayalı Nüfus Kayıt Sistemi Sonuçları.https://biruni.tuik.gov.tr/med as/?kn=101\&locale $=\operatorname{tr}$ (03.01.2020)

Wang, J., Xue, Q., Guo, T., Mei, Z., Long, E., Wen, Q., Huang, W., Luo, T. ve Huang, R. A. 2018. Review on cfd simulating method for biogas fermentation material fluid. Renewable and Sustainable Energy Reviews. 97: 64-73.

Wikipedia, 2020. Doğu Anadolu Bölgesi. https://tr.wikipedia.org (07.01.2020)

Yetiş, A. D., Gazigil, L., Yetiş, R. ve Çelikezen, B. 2019. Hayvansal atık kaynaklı biyogaz potansiyeli: Bitlis örneği. Akademik Platform Mühendislik ve Fen Bilimleri Dergisi. 7 (1): 74-78.

Yürük, F. ve Erdoğmuş, P. 2015. Düzce ilinin hayvansal atıklardan üretilebilecek biyogaz potansiyeli ve k-means kümeleme ile optimum tesis konumunun belirlenmesi. Ileri Teknoloji Bilimleri Dergisi. 4 (1): 47-56. 